\title{
Insulin regulates the novel adipokine adipolin/CTRP12: in vivo and ex vivo effects
}

\author{
Bee K Tan ${ }^{1,2}$, Krzysztof C Lewandowski ${ }^{3}$, Joseph Paul O’Hare ${ }^{1}$ and Harpal S Randeva \\ ${ }^{1}$ Warwick Medical School, University of Warwick, Coventry CV4 7AL, UK \\ ${ }^{2}$ Department of Obstetrics and Gynaecology, Birmingham Heartlands Hospital, Heart of England NHS \\ Foundation Trust, Birmingham, UK \\ ${ }^{3}$ Department of Endocrinology and Metabolic Diseases, Polish Mother's Memorial Research Institute, \\ The Medical University of Lodz, Lodz, Poland
}

Correspondence should be addressed to B K Tan or H S Randeva Emails

B.K.Tan@warwick.ac.uk or Harpal.Randeva@ warwick.ac.uk

\begin{abstract}
There has been intense interest in the adipokines of the C1q complement/TNF-related protein (CTRP) superfamily. Adipolin (CTRP12) has been described as a novel adipokine, abundantly expressed in adipose tissue with insulin-sensitising and anti-inflammatory effects. We wanted to investigate the effects of acute and chronic hyperinsulinaemia on circulating adipolin concentrations (ELISA) via a prolonged insulin-glucose infusion in humans. We also examined the effects of insulin and the insulin sensitiser, rosiglitazone, on adipolin concentrations (western blotting) in human adipose tissue explants. We found that hyperinsulinaemic induction in healthy lean human subjects significantly increased circulating levels of adipolin $(P<0.05$ and $P<0.01)$. Furthermore, in subcutaneous adipose tissue explants, insulin significantly increased adipolin protein expression and secretion $(P<0.05$ and $P<0.01)$. This effect was attenuated by the phosphatidylinositol 3-kinase inhibitor, LY294002 $(P<0.05)$. Moreover, the insulin-sensitising peroxisome proliferator-activated receptor $\gamma($ PPAR $\gamma$ ) agonist, rosiglitazone, significantly increased adipolin protein expression and secretion in subcutaneous adipose tissue explants $(P<0.05$ and $P<0.01)$. This effect was inhibited by the PPAR $\gamma$ antagonist, GW9662 $(P<0.05)$. Our data provide novel insights into adipolin physiology in human subjects.
\end{abstract}
Key Words
- adipokine
- adipolin
- insulin
- PI3K
- rosiglitazone

Journal of Endocrinology (2014) 221, 111-119

\section{Introduction}

Obesity and the metabolic syndrome are associated with insulin resistance, hyperinsulinaemia, type 2 diabetes mellitus (T2DM) and serious cardiovascular sequelae (Eckel et al. 2005).

Adipose tissue produces cytokines termed 'adipokines' that are implicated in the pathogenesis of the metabolic syndrome, T2DM and cardiovascular disease (Kershaw \& Flier 2004).

Adipolin (CTRP12) is a novel adipokine, abundantly expressed in adipose tissue, higher in subcutaneous compared with visceral adipose tissue depots and more highly expressed in adipocytes than in the stromal vascular fraction (Enomoto et al. 2011). Adipolin has insulinsensitising actions by suppressing gluconeogenesis and promoting glucose uptake in hepatocytes as well as adipocytes (Wei et al. 2012b). Adipolin also has anti-inflammatory effects, i.e. adipolin administration reduces macrophage accumulation and pro-inflammatory gene expression in the adipose tissue of obese mice, and conditioned media from adipolin-expressing cells diminished the expression of pro-inflammatory cytokines in response to stimulation with lipopolysaccharide (LPS) or 
tumour necrosis factor $\alpha$ (TNF $\alpha$ ) in cultured macrophages (Enomoto et al. 2011). Furthermore, insulin and rosiglitazone increase adipolin expression in mouse adipocytes (Wei et al. 2012b). However, to date, adipolin receptors have yet to be determined. Recently, we had reported that circulating and adipose tissue adipolin levels are significantly lower in women with polycystic ovary syndrome (PCOS), a pro-inflammatory and insulin-resistant state associated with obesity and T2DM (Tan et al. 2013).

Adipolin appears to have at least two isoforms in vivo (Wei et al. 2012a). Crucially, the two adipolin isoforms vary in oligomeric structures and function differently (Wei et al. 2012a). Full-length adipolin isoform forms trimers and larger complexes but the cleaved globular adipolin isoform consists of mainly dimers (Wei et al. 2012a). Whereas full-length adipolin activated Akt signalling in H4IIE hepatocytes and 3T3-L1 adipocytes, globular adipolin activated MAPK (ERK1/2 and p38 MAPK) signalling instead (Wei et al. 2012a). Only full-length adipolin enhanced insulin-induced glucose uptake in adipocytes (Wei et al. 2012a). Furthermore, there are significantly lower concentrations of full-length and total (full-length and globular) adipolin in diet-induced obese mice, leading to an increase in the ratio of globular:full-length adipolin, possibly through upregulation of furin in adipose tissue (Enomoto et al. 2012). In addition, genetic studies in mice have shown that the loss of Krüppel-like factor 3 leads to upregulation of adipolin (Bell-Anderson et al. 2013); on the other hand, loss of Krüppel-like factor 15 resulted in a decrease in adipolin levels (Enomoto et al. 2013).

Therefore, we wanted to investigate the circulating adipolin levels in response to a metabolic challenge. To achieve this objective, we examined the effects of acute and chronic hyperinsulinaemia on circulating adipolin levels via a prolonged insulin-glucose infusion in healthy lean human subjects. We also examined the effects of insulin and the insulin sensitiser, rosiglitazone, on adipolin concentrations in human adipose tissue explants.

\section{Subjects and methods}

\section{Subjects}

Study 1 Our aim was to investigate the effects of a prolonged insulin-glucose infusion on serum adipolin concentrations in six healthy subjects (three females and three males; Table 1). In order to study the variation in circulating adipolin levels, on day 1 , we measured fasting adipolin levels at $30 \mathrm{~min}$ intervals from 0800 to $1000 \mathrm{~h}$. Adipolin levels were then measured at 2-h intervals until
Table 1 Demographic data. Data are mean \pm s.D.

\begin{tabular}{|c|c|c|}
\hline Variable & $\begin{array}{l}\text { Study } 1(n=6 ; \\
\text { three females and } \\
\text { three males) }\end{array}$ & $\begin{array}{c}\text { Study } 2 \text { ( } n=6 ; \\
\text { six females) }\end{array}$ \\
\hline Age (years) & $26.5 \pm 8.0$ & $28.5 \pm 1.7$ \\
\hline BMI $\left(\mathrm{kg} / \mathrm{m}^{2}\right)$ & $23.2 \pm 2.5$ & $24.8 \pm 0.4$ \\
\hline Glucose $(\mathrm{mmol} / \mathrm{l})$ & $4.3 \pm 0.5$ & $4.3 \pm 0.1$ \\
\hline Insulin (pmol/l) & $78.1 \pm 12.0$ & $60.0 \pm 6.7$ \\
\hline Cholesterol (mmol/l) & $4.1 \pm 0.5$ & $4.0 \pm 0.2$ \\
\hline Triglycerides (mmol/l) & $0.7 \pm 0.1$ & $0.6 \pm 0.1$ \\
\hline
\end{tabular}

$2400 \mathrm{~h}$ and then at $0400 \mathrm{~h}$ as well as at 30-min intervals from 0800 to $1000 \mathrm{~h}$ on day 2 . On the following day, the same subjects were subjected to a prolonged insulin-glucose infusion for $26 \mathrm{~h}$ beginning at $0800 \mathrm{~h}$. Insulin (Human Actrapid) was administered i.v. as a priming dose of $0.04 \mathrm{U} / \mathrm{kg}$ followed by a continuous infusion of $0.5 \mathrm{mU} / \mathrm{kg}$ per min. By choosing this rate of insulin infusion, we expected to achieve hyperinsulinaemia with an approximate four- to sixfold elevation of basal insulin levels, such a rise being similar to the peak insulin levels observed during a $75 \mathrm{~g}$ oral glucose tolerance test (Lewandowski et al. 2001). Fasting blood samples were drawn at $30 \mathrm{~min}$ intervals between 0800 and $1000 \mathrm{~h}$ on days 1 and 2 of the prolonged insulin-glucose infusion (the first and the last $2 \mathrm{~h}$ of the infusion). Intermediate blood samples (all subjects did not eat but drank water) were taken at 2-h intervals until $2400 \mathrm{~h}$ and then at $0400 \mathrm{~h}$ on day 2. Circulating glucose levels were maintained between 4.0 and $6.0 \mathrm{mmol} / \mathrm{l}$. For this study, blood samples were collected from the subjects of University Hospitals Coventry and Warwickshire NHS Trust. From whole blood, serum was immediately separated, aliquoted and stored at $-80^{\circ} \mathrm{C}$ until required.

Study 2 Our aim was to reconstruct as close as possible the physiological environment of adipose tissue, given that adipolin is most highly expressed in adipose tissue (Enomoto et al. 2011), in order to further clarify our observations in Study 1. Thus, we examined the effects of insulin and the insulin sensitiser, rosiglitazone, on adipolin concentrations in human adipose tissue explants. Organ culture of adipose tissue has the major strength of maintaining the expression of adipose tissue-secreted molecules (Fried \& Moustaid-Moussa 2001), and the preservation of paracrine interactions among cells, which are crucial to adipose tissue physiology (Ghorbani \& Abedinzade 2013). All women had no discernible cause for infertility (unexplained infertility). All subjects that were studied did not have endometriosis. Subjects were initially seen at the infertility clinic at University Hospitals

Published by Bioscientifica Ltd. 
Coventry and Warwickshire NHS Trust and then scheduled for laparoscopy in order to assess fallopian tube(s) patency. All subjects underwent anthropometric measurements. After an overnight fast, subcutaneous and omental adipose tissues were obtained (0800-1000 h) from six healthy adult female patients (Table 1) undergoing elective surgery (laparoscopy) for infertility investigation. The fat biopsies were placed in a sterile container containing Medium 199 (Sigma-Aldrich) for primary adipose tissue culture. Subjects were recruited consecutively from the infertility clinic in accordance with the inclusion/exclusion criteria.

Exclusion criteria for all subjects (Study 1 and Study 2) included cardiovascular disease, thyroid disease, neoplasms, current smoking, T2DM, hypertension (blood pressure $>140 / 90 \mathrm{mmHg}$ ) and renal impairment (serum creatinine $>120 \mu \mathrm{mol} / \mathrm{l}$ ). None of these subjects were on any medications for at least 6 months prior to the study, including steroids, anti-diabetic and anti-obesity drugs, lipid-lowering agents or anti-hypertensive medication. The Local Research Ethics Committee approved the studies and all patients involved gave their informed consent, in accordance with the guidelines in the Declaration of Helsinki 2000.

\section{Assays}

Assays for glucose, cholesterol and triglycerides were performed using an automated analyzer (Abbott Architect, Abbott Laboratories). Serum insulin was measured by RIA (Pharmacia). Peroxisome proliferator-activated receptor $\gamma$ $(\operatorname{PPAR} \gamma)$ activity was measured using a commercially available PPAR $\gamma$ transcription factor assay kit (Cayman Chemical, Ann Arbor, MI, USA), according to manufacturer's protocol. Adiponectin levels in conditioned media were measured using a commercially available RIA Kit (Millipore, Watford, UK), according to manufacturer's protocol, with an intra-assay coefficient of variation (CV) of $3.4 \%$. Serum samples were pooled for the various time points (except for $0400 \mathrm{~h}$ on day 2, when we had adequate samples to perform experiments in triplicate) as follows: 0800, 0830, 0900, 0930 and $1000 \mathrm{~h}$ (days 1 and 2); 1200 and 1400 h; 1600 and 1800 h; 2200 and 2400 h. Adipolin concentrations in sera and conditioned media were measured using a commercially available ELISA Kit (Aviscera, Santa Clara, CA, USA), according to manufacturer's protocol, with an intra-assay $\mathrm{CV}$ of $<8 \%$.

Concentration of conditioned media Conditioned media were collected in sterile Eppendorf tubes and spun to remove debris. Afterwards, the supernatant was subjected to vacuum centrifugation in a CentriVap Centrifugal Concentrator as per manufacturer's instructions (Labconco, Kansas City, MO, USA). Protein levels in concentrated samples of conditioned media were quantified using a bicinchoninic acid protein quantification assay kit as per manufacturer's protocol (Thermo Scientific, Rockford, IL, USA). Conditioned media, equalised for protein concentrations, were subsequently assayed for adipolin and adiponectin concentrations. This step was necessary, given the low concentrations of adipolin in conditioned media.

\section{Primary explant culture}

Adipose tissue organ explants were cultured using a protocol that was a modification of the method described by Fried \& Moustaid-Moussa (2001). Briefly, 1-3 g adipose tissue were minced into $5-10 \mathrm{mg}\left(\sim 1 \mathrm{~mm}^{3}\right)$ fragments, washed with a $230 \mu \mathrm{m}$ mesh (Filter no. 60, Sigma-Aldrich) and rinsed with sterile PBS warmed to $37^{\circ} \mathrm{C}$. Samples were then transferred to six-well plates ( $\sim 50 \mathrm{mg} /$ well) containing $3 \mathrm{ml}$ Media 199 (Invitrogen) supplemented with $50 \mu \mathrm{g} / \mathrm{ml}$ gentamicin and $1 \%$ FCS and cultured for $24 \mathrm{~h}$ with or without the addition of insulin (Sigma-Aldrich), MAPK (MEK) inhibitor (U0126; Calbiochem, San Diego, CA, USA), phosphatidylinositol 3-kinase (PI3K) inhibitor (LY294002; Calbiochem), rosiglitazone (Sigma-Aldrich) or PPAR $\gamma$ inhibitor (GW9662; Sigma-Aldrich) in a $37^{\circ} \mathrm{C}$ incubator in an atmosphere of $5 \% \mathrm{CO}_{2} / 95 \%$ air. GW9662 acts as a potent antagonist of PPAR $\gamma\left(\mathrm{IC}_{50}, 7.6 \mathrm{nM}\right)$ via irreversible covalent modification of a cysteine residue (Cys285) in PPAR $\gamma$ 's ligand-binding domain (Rizzo et al. 2006).

\section{Western blotting}

Protein lysates were prepared by homogenising adipose tissue in a radioimmunoprecipitation lysis buffer $(0.5 \mathrm{M}$ Tris-HCl, pH 7.4, 1.5 M NaCl, 2.5\% deoxycholic acid, 10\% NP-40 and 10 mM EDTA; Upstate, Lake Placid, NY, USA) according to manufacturer's instructions. Protein samples (35 $\mu \mathrm{g} /$ lane) containing SDS-sample buffer (5 Murea, $0.17 \mathrm{M}$ SDS, $0.4 \mathrm{M}$ dithiothreitol and $50 \mathrm{mM}$ Tris- $\mathrm{HCl}, \mathrm{pH} 8.0$ ) were subjected to SDS-PAGE (10\% resolving gel) and transferred onto PVDF membranes (Millipore). PVDF membranes were blocked in Tris-buffered saline (TBS) containing 0.1\% Tween 20 and 5\% BSA for two h. The PVDF membranes were then incubated with polyclonal primary rabbit-anti-human antibody for adipolin (LifeSpan Biosciences, Seattle, WA, USA; 1:500 dilution) or polyclonal primary rabbit-anti-human antibody for

Published by Bioscientifica Ltd. 
adiponectin (Santa Cruz Biotechnology, Inc., Biosciences; 1:1000 dilution) or polyclonal primary rabbit-anti-human antibody for phospho-Akt (Thr308; Cell Signaling Technology, Inc., Beverly, MA, USA; 1:1000 dilution) or polyclonal primary rabbit-anti-human antibody for phospho-Erk1/2 (Cell Signaling Technology, Inc.; 1:1000 dilution) overnight at $4{ }^{\circ} \mathrm{C}$. The membranes were washed thoroughly for 60 min with TBS containing $0.1 \%$ Tween 20 before incubation with the secondary anti-rabbit HRP-conjugated immunoglobulin (Dako, Ely, UK; 1:2000), for $1 \mathrm{~h}$ at room temperature. Antibody complexes were visualised using chemiluminescence (ECL + ; GE Healthcare, Little Chalfont, UK). Human adipolin (Aviscera) and human adiponectin (Phoenix Pharmaceuticals, Burlingame, CA, USA) were used as positive controls and water as a negative control (data not shown). For standardisation, the same membranes were stripped and reprobed using monoclonal primary rabbit-anti-human antibody for $\beta$-actin (Cell Signaling Technology, Inc.; 1:1000 dilution) or polyclonal primary rabbit-anti-human antibodies for total Akt (Cell Signaling Technology, Inc.; 1:1000 dilution) or total Erk1/2 (Cell Signaling Technology, Inc.; 1:1000 dilution).

Data analysis The densities were measured using a scanning densitometer coupled to scanning software Scion Image (Scion Corporation, Frederick, MD, USA). Standard curves were generated to ensure linearity of signal intensity over the range of protein amounts loaded into gel lanes. Comparisons of densitometric signal intensities were made only within this linearity range.

\section{Statistical analysis}

Data were analysed by ANOVA (post hoc analysis: Dunnett's test; GraphPad Prism 6; GraphPad Software, San Diego, CA, USA). $P<0.05$ was considered significant.

\section{Results}

Effects of a prolonged insulin-glucose infusion on serum adipolin levels

Serum adipolin levels remained unaltered throughout the control day between 0800 and $1000 \mathrm{~h}$ to between 0800 and $1000 \mathrm{~h}$ the next day in all subjects, female only as well as male only subjects (Fig. 1A, B and C; $P>0.05$ ). There were no significant differences between female and male subjects (Fig. 1D; $P>0.05$ ).

Insulin infusion resulted in an elevation of fasting insulin levels from $78.1 \pm 12.0$ to $294.6 \pm 31.0 \mathrm{pmol} / \mathrm{l}$.
Insulin remained elevated until the end of the prolonged insulin-glucose infusion $(366.0 \pm 37.0 \mathrm{pmol} / \mathrm{l})$.

Insulin infusion significantly increased serum adipolin concentrations in all subjects, female only as well as male only subjects (Fig. $1 \mathrm{~A}, \mathrm{~B}$ and $\mathrm{C}$; ${ }^{*} P<0.05$ and $\left.{ }^{* *} P<0.01\right)$. The increase in serum adipolin levels was relatively acute approaching maximal values after $4 \mathrm{~h}$ $\left(1.97 \pm 0.13 \mathrm{ng} / \mathrm{ml}\right.$; Fig. $\left.1 \mathrm{~A} ;{ }^{* *} \mathrm{P}<0.01\right)$ and persisting throughout the entire period of hyperinsulinaemia. There were no significant differences between female and male subjects (Fig. 1E; $P>0.05$ ).

\section{Concentration-dependent effects of insulin on adipolin protein expression and secretion into conditioned media in control human subcutaneous adipose tissue explants}

Adipolin protein concentrations were found to be higher in subcutaneous adipose tissue, when compared with omental adipose tissue. The average relative protein expression of adipolin between subcutaneous and omental adipose tissue was 1.48:1. Hence, we focused on subcutaneous adipose tissue for our primary adipose tissue explant studies. Optimisation experiments were performed to select the optimal concentration and time point. We found that insulin significantly increased adipolin protein expression and secretion in control human subcutaneous adipose tissue explants (Fig. 2A and $\mathrm{B} ;{ }^{*} P<0.05$ and $\left.{ }^{*} P<0.01\right)$. These effects were significantly attenuated by the PI3K inhibitor (LY294002; $50 \mu \mathrm{M}$ ) but not by the MEK inhibitor (U0126; $25 \mu \mathrm{M}$ ) (Fig. 2C and D; ${ }^{*} P<0.05$ and ${ }^{\# \#} P<0.01$ ).

\section{Concentration-dependent effects of rosiglitazone on adipolin protein expression and secretion into conditioned media in control human subcutaneous adipose tissue explants}

Given the effects of insulin on adipolin expression and secretion in adipose tissue, we studied the effect of the insulin-sensitising $\operatorname{PPAR} \gamma$ agonist, rosiglitazone, on adipolin expression and secretion in adipose tissue. Optimisation experiments were performed to select the optimal concentration and time point. Rosiglitazone significantly increased adipolin protein expression and secretion in control human subcutaneous adipose tissue explants (Fig. 2E and F; ${ }^{*} P<0.05$ and ${ }^{*} P<0.01$ ). This effect was attenuated by the PPAR $\gamma$ inhibitor (GW9662; $10 \mu \mathrm{M}$; Fig. $2 \mathrm{G}$ and $\mathrm{H} ;{ }^{*} P<0.05$ and $\left.{ }^{\# \#} P<0.01\right)$. Adiponectin expression and secretion in

Published by Bioscientifica Ltd. 

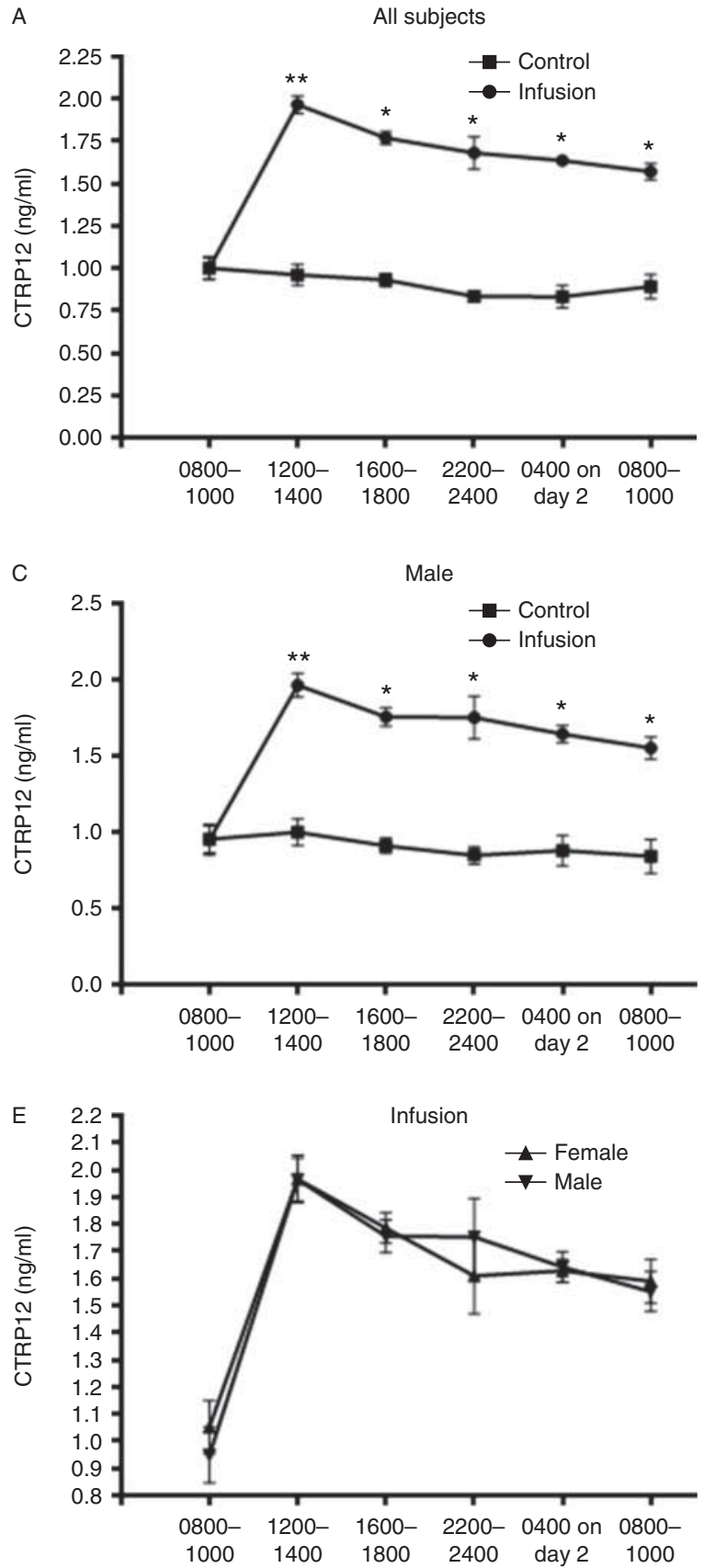

B

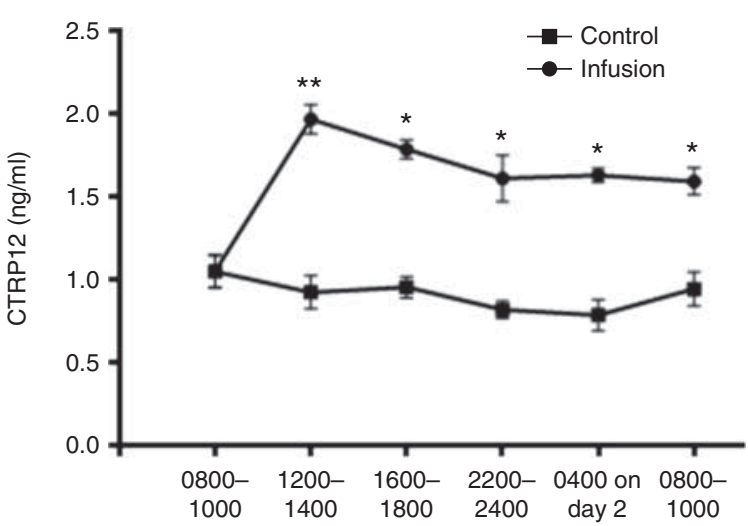

D

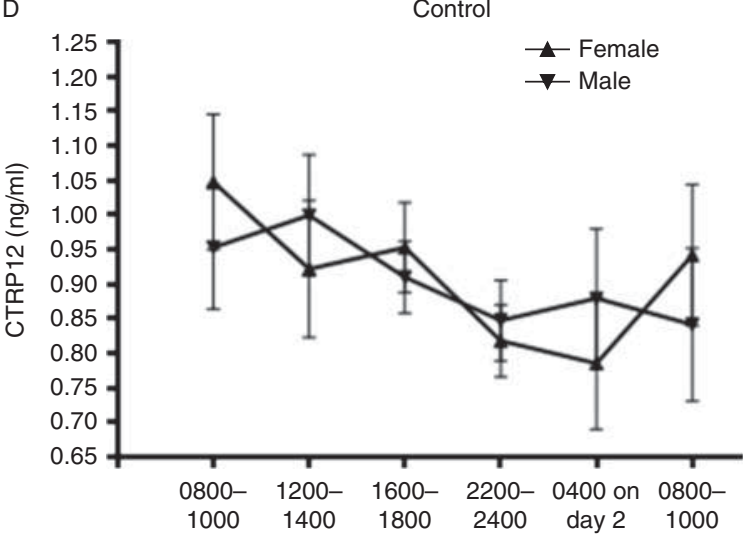

\begin{tabular}{|c|c|c|c|c|c|c|c|}
\hline Time (h) & 0800 & 0800-1000 & $1200-1400$ & $1600-1800$ & $2200-2400$ & 0400 on day 2 & 0800-1000 \\
\hline Insulin (pmol/l) & $78.1 \pm 12.0$ & $276.3 \pm 25.1$ & $294.6 \pm 31.0$ & $345.4 \pm 31.7$ & $365.1 \pm 38.1$ & $339.7 \pm 32.5$ & $366.0 \pm 37.0$ \\
\hline Glucose (mmol/l) & $4.3 \pm 0.5$ & $4.8 \pm 0.6$ & $4.3 \pm 0.7$ & $5.6 \pm 0.9$ & $5.2 \pm 0.5$ & $4.4 \pm 1.0$ & $4.7 \pm 0.8$ \\
\hline $10 \%$ Glucose infusion $(\mathrm{ml} / \mathrm{h})$ & - & $116.2 \pm 11.9$ & $120.4 \pm 8.9$ & $122.5 \pm 11.4$ & $125.8 \pm 9.3$ & $138.3 \pm 11.7$ & $128.3 \pm 13.2$ \\
\hline
\end{tabular}

Figure 1

Mean concentrations of adipolin before and during the prolonged insulin-glucose infusion in (A) all subjects, (B) female only subjects and (C) male only subjects; mean concentrations of adipolin before (D) and during (E) the prolonged insulin-glucose infusion in all subjects. Data are mean \pm s.D. Group comparison by ANOVA and post hoc Dunnett's test. * $P<0.05$ and $* * P<0.01$. 
A
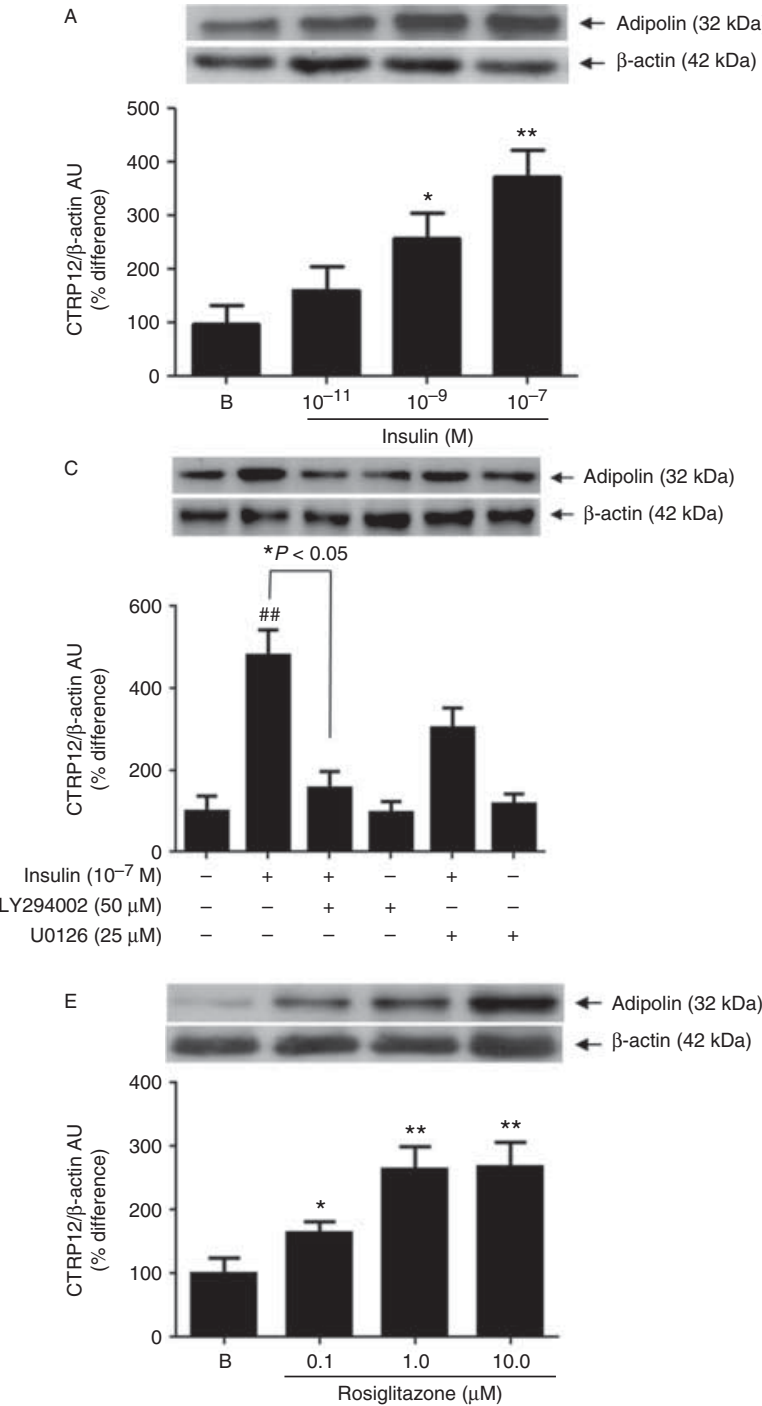

G
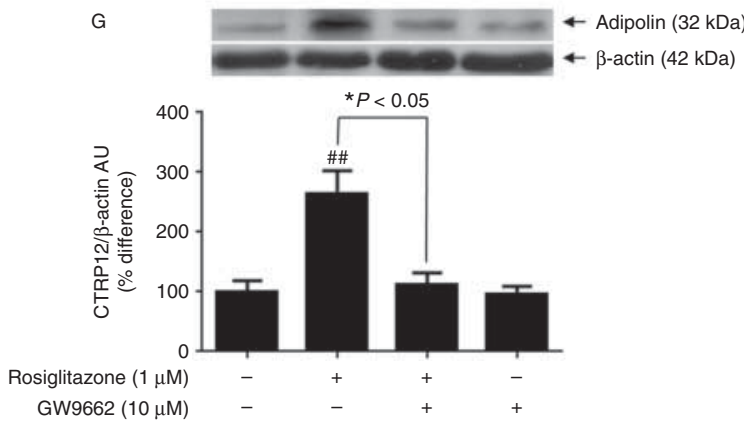

GW9662 $(10 \mu \mathrm{M})$
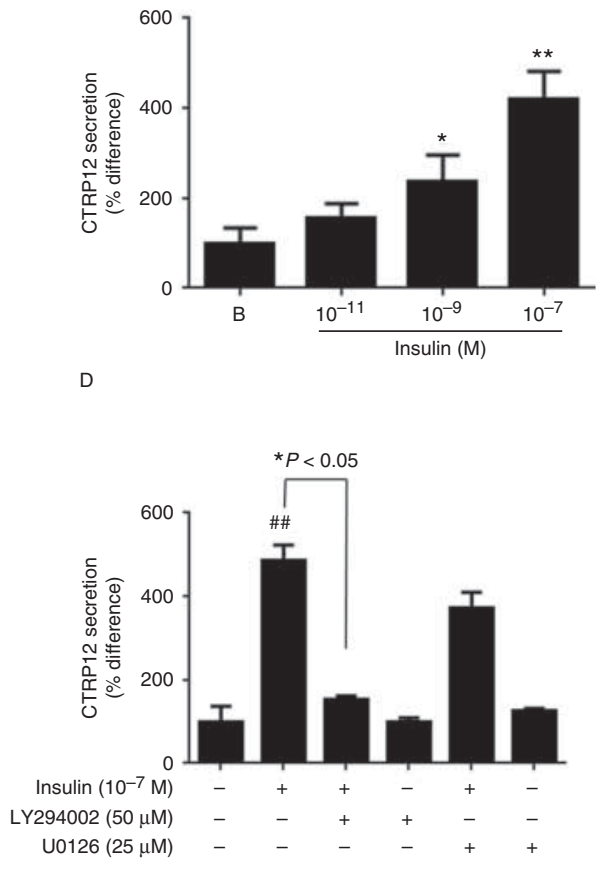

$\mathrm{F}$

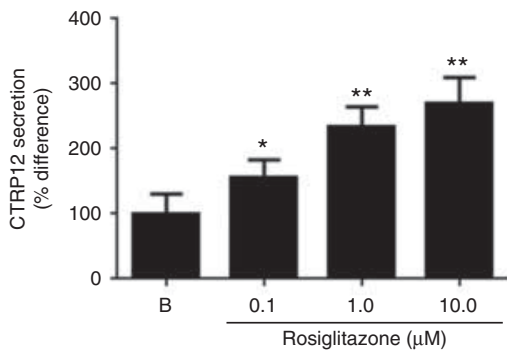

$\mathrm{H}$

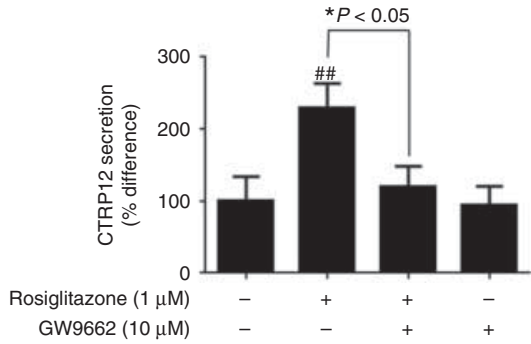

Figure 2

Concentration-dependent effects of insulin $\left(10^{-11}, 10^{-9}\right.$ and $\left.10^{-7} \mathrm{~mol} / \mathrm{l}\right)$ on (A) adipolin protein expression and (B) secretion in control human subcutaneous adipose tissue explants at $24 \mathrm{~h}$; effect of PI3K (LY294002; $50 \mu \mathrm{M})$ and MEK (U0126; $25 \mu \mathrm{M})$ inhibitors on insulin $\left(10^{-7} \mathrm{~mol} / \mathrm{l}\right)$-induced (C) adipolin protein expression and (D) secretion in human subcutaneous adipose tissue explants at $24 \mathrm{~h}$. Concentration-dependent effects of rosiglitazone $(0.1,1.0$ and $10.0 \mu \mathrm{M})$ on $(\mathrm{E})$ adipolin protein expression and (F) secretion in control human subcutaneous adipose tissue explants at
$24 \mathrm{~h}$; effect of PPAR $\gamma$ antagonist (GW9662; $10 \mu \mathrm{M}$ ) on rosiglitazone $(1.0 \mu \mathrm{M})$-induced $(\mathrm{G})$ adipolin protein expression and $(\mathrm{H})$ secretion in human subcutaneous adipose tissue explants at $24 \mathrm{~h}$. Data are expressed as percent difference of mean of basal. Each experiment was carried out with six different samples from six different control subjects in three replicates. Group comparison was done by ANOVA and post hoc Dunnett's test. ${ }^{*} P<0.05,{ }^{* *} P<0.01$ and ${ }^{\# \#} P<0.01$. AU, arbitrary units. http://joe.endocrinology-journals.org DOI: 10.1530/JOE-13-0537
C 2014 Society for Endocrinology Printed in Great Britain 


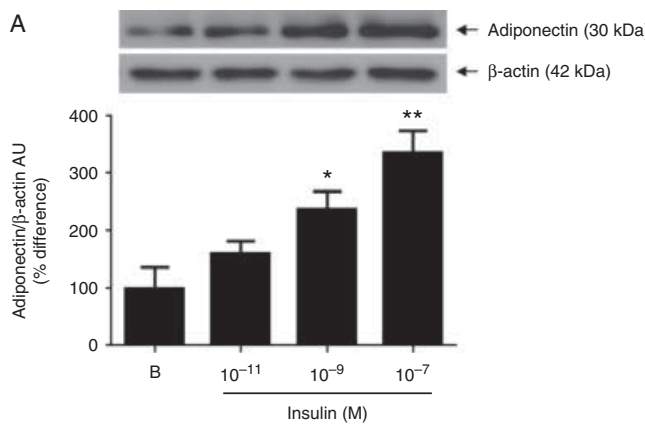

B
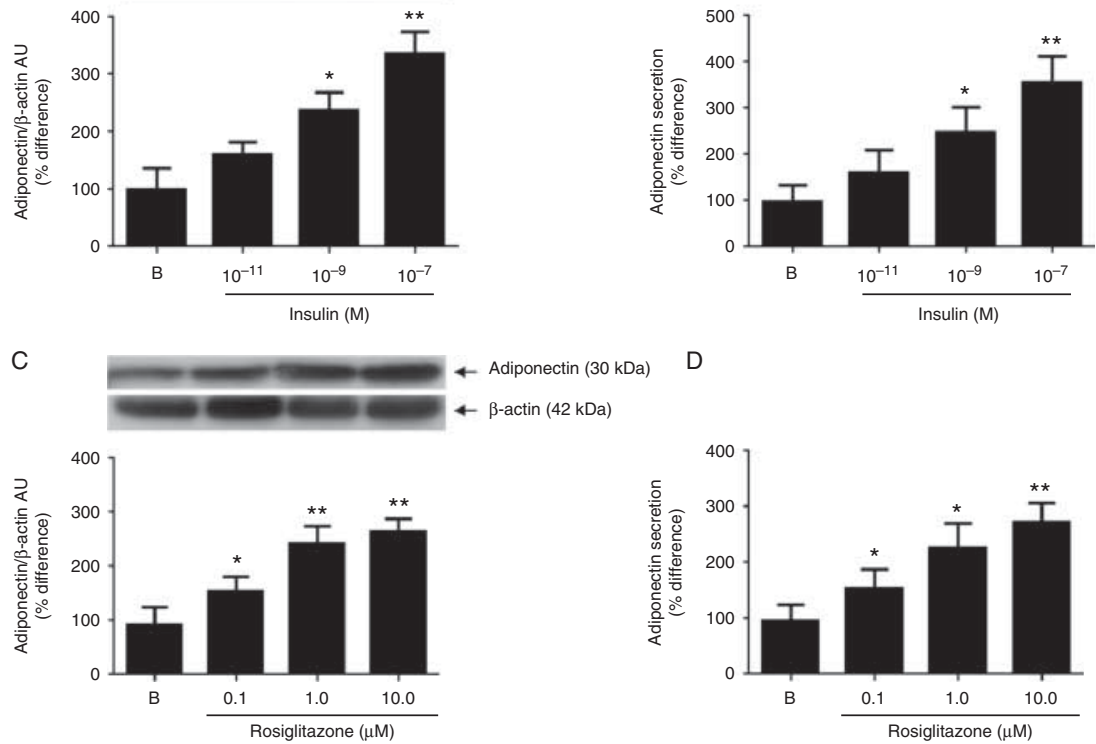

\section{Figure 3}

Concentration-dependent effects of insulin $\left(10^{-11}, 10^{-9}\right.$ and $\left.10^{-7} \mathrm{~mol} / \mathrm{l}\right)$ on (A) adiponectin protein expression and (B) secretion in control human subcutaneous adipose tissue explants at $24 \mathrm{~h}$. Concentration-dependent effects of rosiglitazone $(0.1,1.0$ and $10.0 \mu \mathrm{M})$ on (C) adiponectin protein expression and (D) secretion in control human subcutaneous adipose tissue

response to insulin and rosiglitazone served as positive controls (Fig. 3A, B, C and D).

\section{Discussion}

This is the first study in humans on the regulation of adipolin by insulin and rosiglitazone, a recently established adipokine with insulin-sensitising and anti-inflammatory effects (Enomoto et al. 2011, Wei et al. 2012b).

We present novel data of a profound increase in adipolin during a prolonged $(26 \mathrm{~h})$ insulin-glucose infusion. We also show that insulin stimulates adipolin expression in human subcutaneous adipose tissue. Furthermore, our findings highlight the involvement of the PI3K pathway in the regulation of insulin-induced adipolin protein expression and secretion in human subcutaneous adipose tissue. Recently, it was reported that the adipose tissue PI3K signalling pathway is impaired in obese rodents (McCurdy et al. 2012). Since adipolin levels are low in obesity, it will be of interest to ascertain as to whether the decrease in PI3K activity in adipose tissue is a contributory mechanism underlying the lower adipose tissue and circulating adipolin levels. Of relevance, insulin-induced adiponectin (foremost adipokine of the explants at $24 \mathrm{~h}$. Data are expressed as percent difference of mean of basal. Each experiment was carried out with six different samples from six different control subjects in three replicates. Group comparison was done by ANOVA and post hoc Dunnett's test. ${ }^{*} P<0.05$ and ${ }^{*} P<0.01$. $A U$, arbitrary units.

C1q complement/TNF-related protein (CTRP) superfamily) secretion from adipocytes has also been reported to be regulated by the PI3K pathway (Cong et al. 2007). Finally, our results on rosiglitazone and the PPAR $\gamma$ inhibitor (GW9662) highlight the importance of the PPAR $\gamma$ transcriptional pathway in adipolin expression in human adipose tissue. Taken together, the PI3K/PPAR $\gamma$ pathway, a crucial regulator of insulin's metabolic functions (Kim \& Chen 2004), determines adipolin concentrations in human adipose tissue.

Our findings indicate that an increase in adipolin levels is consequent to an acute stimulation by exogenous insulin. However, our recent report in women with PCOS showed that lower adipolin levels were observed in these hyperinsulinaemia-associated conditions (Tan et al. 2013). In relation to this, Enomoto et al. (2011) had reported that adipolin transcript levels were markedly suppressed in cultured adipocytes by palmitic acid, the endoplasmic reticulum stress-inducer tunicamycin or TNF $\alpha$. Obesity is a low-grade chronic inflammatory state characterised by increased levels of saturated fatty acids, conditions of which lead to endoplasmic reticulum stress in adipocytes (Enomoto et al. 2011), as well as low Krüppel-like factor 15 levels (Enomoto et al. 2013). Thus, these factors could account for the paradox

Published by Bioscientifica Ltd. 
of low levels of adipolin in obesity (hyperinsulinaemic state). Another possible explanation is that insulin resistance disrupts the insulin-adipolin homeostatic response, which could lead to the lower adipolin levels in obesity and T2DM. Further studies are needed to elucidate this point.

Insulin in euglycaemic conditions appears to exert anti-inflammatory effects by neutralising LPS-induced induction of pro-inflammatory cytokines (Dandona et al. $2009,2010)$. On the other hand, adipolin has antiinflammatory effects, specifically, conditioned media from adipolin-expressing cells diminish the expression of pro-inflammatory cytokines in response to stimulation with LPS in cultured macrophages (Enomoto et al. 2011). Taken together, it is reasonable to postulate that the anti-inflammatory effects of insulin could be dependent, at least in part, on adipolin. This may have significant diagnostic and/or therapeutic implications.

A limitation of our study may relate to the fact that we used a commercially available ELISA kit and a commercially available antibody for adipolin for western blotting, both of which are unable to determine uncleaved and cleaved/ globular forms of adipolin separately. Unravelling the interactions of uncleaved and cleaved/globular forms of adipolin would be important in advancing our knowledge of adipolin biology. Furthermore, due to logistical constraints, we were not able to measure parallel changes in serum adiponectin as well as other inflammatory or anti-inflammatory markers. Moreover, we had not studied the expression levels of adipolin in the sub-populations of cells within adipose tissue. In addition, it would be of interest to study the regulation of adipolin expression in other adipose tissue depots and it would also be useful to elucidate the ex vivo stability of adipolin. Future research should address these points.

It should be emphasised that our study utilised a relatively small number of healthy, lean subjects, and we could only provide data for up to $26 \mathrm{~h}$, because of the challenge imposed by the prolonged insulin-glucose infusion study. Thus, our data represent the physiological (healthy subjects) rather than the pathological (obesity and/or T2DM subjects) response of adipolin to insulin. Nevertheless, our observations provide data on the impact of insulin on adipolin metabolism, which highlight the potential relevance to understand adipolin physiology further in metabolic disease.

\section{Declaration of interest}

The authors declare that there is no conflict of interest that could be perceived as prejudicing the impartiality of the research reported.

\section{Funding}

This work was supported by the General Charities of the City of Coventry.

\section{Author contribution statement}

B K T researched data, contributed to discussion, wrote the manuscript and reviewed/edited the manuscript. $\mathrm{KCL}$ researched data and reviewed/ edited the manuscript. J P O and H S R contributed to discussion and reviewed/edited the manuscript.

\section{Acknowledgements}

H S R acknowledges S Waheguru, University of Warwick, for his continuous support.

\section{References}

Bell-Anderson KS, Funnell AP, Williams H, Mat Jusoh H, Scully T, Lim WF, Burdach JG, Mak KS, Knights AJ, Hoy AJ et al. 2013 Loss of Krüppel-like factor 3 (KLF3/BKLF) leads to upregulation of the insulin-sensitizing factor adipolin(FAM132A/CTRP12/C1qdc2). Diabetes 62 2728-2737. (doi:10.2337/db12-1745)

Cong L, Chen K, Li J, Gao P, Li Q, Mi S, Wu X \& Zhao AZ 2007 Regulation of adiponectin and leptin secretion and expression by insulin through a PI3K-PDE3B dependent mechanism in rat primary adipocytes. Biochemical Journal 403 519-525. (doi:10.1042/BJ20061478)

Dandona P, Chaudhuri A, Ghanim H \& Mohanty P 2009 Insulin as an antiinflammatory and antiatherogenic modulator. Journal of the American College of Cardiology 53 S14-S20. (doi:10.1016/j.jacc.2008.10.038)

Dandona P, Ghanim H, Bandyopadhyay A, Korzeniewski K, Ling Sia C, Dhindsa S \& Chaudhuri A 2010 Insulin suppresses endotoxin-induced oxidative, nitrosative, and inflammatory stress in humans. Diabetes Care 33 2416-2423. (doi:10.2337/dc10-0929)

Eckel RH, Grundy SM \& Zimmet PZ 2005 The metabolic syndrome. Lancet 365 1415-1428. (doi:10.1016/S0140-6736(05)66378-7)

Enomoto T, Ohashi K, Shibata R, Higuchi A, Maruyama S, Izumiya Y, Walsh K, Murohara T \& Ouchi N 2011 Adipolin/C1qdc2/CTRP12 protein functions as an adipokine that improves glucose metabolism. Journal of Biological Chemistry 286 34552-34558. (doi:10.1074/jbc. M111.277319)

Enomoto T, Shibata R, Ohashi K, Kambara T, Kataoka Y, Uemura Y, Yuasa D, Murohara T \& Ouchi N 2012 Regulation of adipolin/ CTRP12 cleavage by obesity. Biochemical and Biophysical Research Communications 428 155-159. (doi:10.1016/j.bbrc.2012.10.031)

Enomoto T, Ohashi K, Shibata R, Kambara T, Uemura Y, Yuasa D, Kataoka Y, Miyabe M, Matsuo K, Joki Y et al. 2013 Transcriptional regulation of an insulin-sensitizing adipokine adipolin/CTRP12 in adipocytes by Krüppel-like factor. PLOS ONE 8 e83183. (doi:10.1371/journal. pone.0083183)

Fried SK \& Moustaid-Moussa N 2001 Culture of adipose tissue and isolated adipocytes. Methods in Molecular Biology 155 197-212. (doi:10.1385/ 1-59259-231-7:197)

Ghorbani A \& Abedinzade M 2013 Comparison of in vitro and in situ methods for studying lipolysis. ISRN Endocrinology 2013205385. (doi:10.1155/2013/205385)

Kershaw EE \& Flier JS 2004 Adipose tissue as an endocrine organ. Journal of Clinical Endocrinology and Metabolism 89 2548-2556. (doi:10.1210/jc.2004-0395)

Kim JE \& Chen J 2004 Regulation of peroxisome proliferator-activated receptor- $\gamma$ activity by mammalian target of rapamycin and amino acids in adipogenesis. Diabetes 53 2748-2756. (doi:10.2337/diabetes.53.11.2748)

Published by Bioscientifica Ltd. 
Lewandowski K, Randeva HS, O'Callaghan CJ, Horn R, Medley GF, Hillhouse EW, Brabant G \& O'Hare P 2001 Effects of insulin and glucocorticoids on the leptin system are mediated through free leptin. Clinical Endocrinology 54 533-539. (doi:10.1046/j.1365-2265.2001. 01243.x)

McCurdy CE, Schenk S, Holliday MJ, Philp A, Houck JA, Patsouris D, MacLean PS, Majka SM, Klemm DJ \& Friedman JE 2012 Attenuated Pik3r1 expression prevents insulin resistance and adipose tissue macrophage accumulation in diet-induced obese mice. Diabetes $\mathbf{6 1}$ 2495-2505. (doi:10.2337/db11-1433)

Rizzo G, Disante M, Mencarelli A, Renga B, Gioiello A, Pellicciari R \& Fiorucci S 2006 The farnesoid X receptor promotes adipocyte differentiation and regulates adipose cell function in vivo. Molecular Pharmacology 70 1164-1173. (doi:10.1124/mol.106.023820)
Tan BK, Chen J, Adya R, Ramanjaneya M, Patel V \& Randeva HS 2013 Metformin increases the novel adipokine adipolin/CTRP12: role of the AMPK pathway. Journal of Endocrinology 219 101-108. (doi:10.1530/ JOE-13-0277)

Wei Z, Lei X, Seldin MM \& Wong GW 2012a Endopeptidase cleavage generates a functionally distinct isoform of $\mathrm{C} 1 \mathrm{q} /$ tumor necrosis factorrelated protein-12 (CTRP12) with an altered oligomeric state and signaling specificity. Journal of Biological Chemistry 287 35804-35814. (doi:10.1074/jbc.M112.365965)

Wei Z, Peterson JM, Lei X, Cebotaru L, Wolfgang MJ, Baldeviano GC \& Wong GW 2012b C1q/TNF-related protein-12 (CTRP12), a novel adipokine that improves insulin sensitivity and glycemic control in mouse models of obesity and diabetes. Journal of Biological Chemistry 287 10301-10315. (doi:10.1074/jbc.M111.303651)

Received in final form 20 January 2014

Accepted 3 February 2014

Accepted Preprint published online 3 February 2014
Published by Bioscientifica Ltd. 